\title{
THE SOMATIC MITOSES OF THE MOSQUITO CULEX PIPIENS
}

ROBERT T. HANCE

Zoological Laboratory, University of Pennsylvania

TWO PLATES

CONTENTS

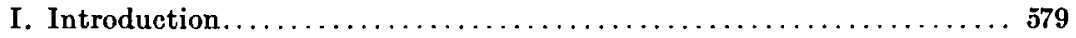

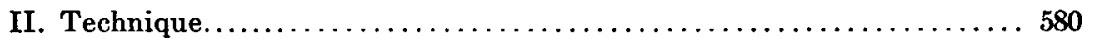

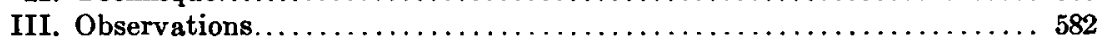

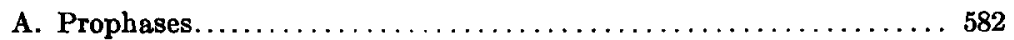

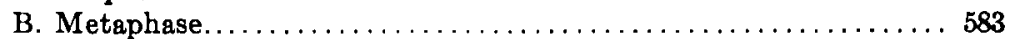

C. Anaphase......................... 584

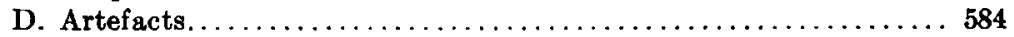

IV. Discussion of results and of the literature $\ldots \ldots \ldots \ldots \ldots \ldots \ldots \ldots 58$

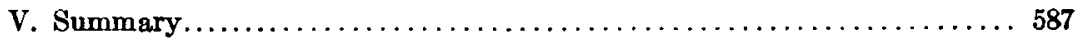

VI. Bibliography $\ldots \ldots \ldots \ldots \ldots \ldots \ldots \ldots \ldots \ldots \ldots \ldots \ldots \ldots \ldots \ldots \ldots$

\section{INTRODUCTION}

The great mass of cytological work has been done on the germ cells, partly because of the abundance of mitotic stages found there, partly because of the greater ease of manipulating this tissue, but largely because of the great theoretical importance of the processes here visible. Beyond a few general sorties into the field of somatic cell division, which determined that the body chromosomes were usually present in the same number as in the reproductive cells, and were, in some instances, at least, similar morphologically, little has been done in the way of thoroughly working out the mitotic mechanism from prophase to telophase.

The ideal investigation into somatic cytology would follow the chromosomes of the fertilized egg as it evolved into the organism and as the cells differentiated into specialized tissues, 
but unfortunately material favorable for the study of development is usually hopeless for cytological work, and the reverse is true. Some success which I have had with mosquito eggs leads me to believe that improved technique would make this insect a favorable form for such a study, but until such a technique has been developed, the study of the division figures found in the larvae of this form will prove, I think, both interesting and valuable. Because of an interest in somatic chromosomes and because of the contradictory reports that have been published on Culex this animal was selected for study. The results are complementary to Mr. Whiting's thesis on the spermatogensis.

In this paper only what may be termed the normal somatic divisions will be considered, as Miss Holt has made a study of the multiple complexes.

It is a pleasure to take this opportunity of thanking Dr. McClung for the many facilities he has placed at my disposal and for his constant interest and advice. Discussions with my fellow workers Dr. Caroline Holt and Dr. P. W. Whiting have been of great assistance to me.

\section{TECHNIQUE}

An abundance of material was found in tubs of water standing in the greenhouses on the Campus. Larvae and pupae have been fixed, but only the larvae show any number of somatic divisions. The question of the method of fixation is an exceedingly important one, as the reasons for the various conclusions reached by other investigators of Culex chromosomes are quite evident from the results obtained with various fixatives. Eight different killing fluids were tried, each at three temperatures, $5^{\circ} \mathrm{C}$., room temperature and $38^{\circ} \mathrm{C}$. Of these the best has proved to be Flemming's solution to which had been added a little urea and used at room temperature. The urea was added to increase the rapidity of penetration. Another fluid which gave good results for some stages was what is designated in this Laboratory as P. F. A. No. 3 which was used at $38^{\circ} \mathrm{C}$. The formula for this fluid is as follows. 


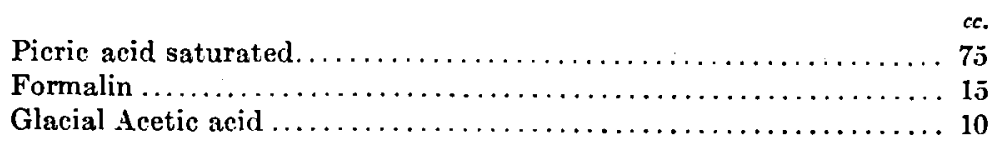

Flemming's solution gave much the more accurate results particularly on the earlier stages. For perfect fixation with this fluid, however, the larvae must be teased finely in the solution or else the chitinous covering will prevent penetration. P. F. A. No 3 gives excellent results on the metaphase chromosomes but the early stages of the chromosomes are very likely to be wholly or partially fused, giving a totally erroneous impression of the actual conditions. When larvae were fixed in this killing fluid the head and thorax were severed from the abdomen and before placing in the warm fluid. Smears of the thorax were made and fixed in Flemming's solution but although thirty animals were prepared in this way no division figures were found. The general fixation was very good.

The material was dehydrated by allowing 95 per cent alcohol to displace the killing fluid drop by drop, until the fixative was entirely eliminated and the tissue stood in 95 per cent alcohol. When Flemming was used the material was first washed in water and then dehydrated in the same way. It was found unnecessary to remove the picric acid completely, as is usually advised following a picric acid fixative. The tissue fixed in P. F. A. No. 3 was cleared in aniline oil and the Flemming material was cleared in cedar oil. Either of these oils was followed with xylol, imbedded in paraffin and cut in sections six micra thick. In imbedding a number of thoraces or bodies the pieces were oriented one behind the other, which simplified the cutting materially (Hance, '15). When finely teased tissue was being prepared for cutting, the material in xylol was poured into a paper box or boat and the xylol was drained off through the paper, leaving the tissue massed at one end of the boat. The paraffin was poured into this paper form and the box was placed in melted paraffin. In this way it was easy to retain the finely divided tissue. Iron alum-haematoxylin was used exclusively in staining. 
The methods of technique practiced here gave results consistent with others obtained in this Laboratory and are part of a number of experiments, employing the same reagents, under similar conditions.

\section{OBSERVATIONS}

Miss Taylor ('15) states that she had trouble in finding somatic mitoses, but I have had very little difficulty in locating active cells. The cells of the general tissues of the body are usually in a resting condition, but the limb buds in the thoracic region and the nervous tissue are frequently full of division figures. It is an interesting fact that the somatic divisions show some indication of rhythms of cell activity. The tissue may be entirely inactive or, when active, a large number of cells are taking part, and the majority of these cells will be in approximately the same stage of division.

I have never found any evidence of synizesis in either germ or somatic tissue, except in cases where the material was obviously very poorly fixed. While it seems evident that there must be some physiological (or probably only physical) peculiarity about the stage in which synizesis is observed which permits it to act differently to the other stages, nevertheless, I believe that the actual appearance of synizesis in fixed material to be an artefact.

Although most of the drawings have been made from mitoses found in the nervous tissue, similar stages have been found in most of the tissues of the body. These include nervous tissue, limb buds, intestine, epithelium, ovarian tissue and Malphigian tubules.

Prophase. The somatic cell in the resting or early prophase condition possesses a nucleolus. This disappears as the chromosome filaments appear. The earliest prophase stages I have found in active tissue are shown in figures 2 to 16 . As can be seen there are three pairs of threads (two long pairs and one shorter pair) present, all more or less closely associated. The importance of the proper fixation in these stages can not be overemphasized as I was misled for some time by finding (in the 
P. F. A. No. 3 fixed material) only three threads with splits occasionally appearing at the ends of the threads. It is easy to understand how, unless the fluid reached the cell almost immediately, the delicate splits or lines of separation would be completely or partially obliterated. Such a case is shown in figure 1 where only three threads appear. It is very interesting to note the orientation of the three pairs of chromatin threads in the prophase. If the plates will be referred to it will be seen that the apices of the three V's in each cell (the point of spindle fiber attachment) are directed toward the same pole, suggesting the position in which the chromosomes lie when last seen in the anaphase. This condition is very suggestive from the point of view of the individuality hypothesis. As the prophases approach metaphase the paired chromatin threads seem to separate and gradually lose the characteristic prophase orientation. The beginning of this process is illustrated in figures 13 to 16 .

I am unable to account, at present, for the size variation which occurs between the chromosomes of various cells. This will be apparent chiefly in the drawings of the prophase figures. Figure 7 is of an especially large cell. It will be noticed that the size relationship between the chromosomes of the same cell is apparently the same in all cases.

Metaphase. When the arrangement of the prophase is completely lost, the threads have shortened and thickened, have separated rather widely and the characteristic metaphase plate stage appears, figures 17 to 24,26 to 30 . This stage Whiting has designated as stage $A$. The chromosomes undergo another rearrangement and the three pairs line up side by side preparatory to division (Whiting's stage B), figures 25 and 31. A good side view of the spindle with the chromosomes distinctly visible is difficult to find but figures 32,33 and 34 were drawn from clear cells in which the plates were slightly tilted permitting the six chromosomes on the spindle, each split preparatory to division, to be seen. Spindle fibers are visible but their actual attachment to the chromosomes is not evident. Judging from the anaphase figures, however, (fig. $37 a$ ) it seems evident that the fiber is attached to the apex of the $V$. 
Anaphase. Clear anaphase figures are exceedingly difficult to find and the chromosomes are likely to be fused as in figures 38 and 39, giving a wrong impression of the real conditions. It would appear from these figures that three chromosomes are drawn to either pole, whereas in reality the drawings represent six chromosomes, as shown in figures 35,36 and 37 , the apices of whose V's have fused. In figures 35 and 36 six chromosomes are to be seen being drawn to either pole. Though these appear as rods they are in reality $\mathrm{Vs}$, one arm of which is under the arm figured. In these cases the V-nature of the chromosomes can be determined by focusing. This condition is shown in figure $37 a$ where one of the pairs has been twisted into the plane of the section. Figure 40 shows six chromosomes in anaphase from a polar view. There seems to be a tendency for the anaphase chromosomes of the somatic cells to turn slightly at right angles to the plane in which they separate, as Whiting has reported for the germ cells. In figure 36 the ends of the chromosomes are all tilted vertically to the plane of the paper. Whether this is due merely to the angle at which the arm of a $\mathrm{V}$ might lie or is a real change of axis, I am not certain.

Artefacts. In all stages of mitosis in poorly fixed material are to be found expressions of the faulty technique. A fairly complete gradation of fixation may be found which helps to indicate how other investigators (Seiler and Taylor) may have been led astray in their studies of the chromosomes of Culex. In cells so exceedingly small as these the minute separations would be very quickly obliterated if they were not immediately preserved by the killing agent. The fusion of the chromatin elements is a very common occurrence unless great care is taken to preserve the tissue properly, as I have shown in a paper to be published shortly on mammalian technique. (Hance '17.)

\section{DISCUSSION OF RESULTS AND OF THE LITERATURE}

The above account of the somatic mitoses has shown that there are six chromosomes in the body cells, corresponding in size and position to the six chromosomes of the spermatogonia found by Metz ('16) and Whiting (in this journal). In describ- 
ing the ovogonial and spermatogonial chromsomes Miss Stevens ('10) has reported much the same cytological conditions in Culex pipiens as have been found by Metz and Whiting. "Each of the six chromosomes divides longitudinally, and the pairing of the daughter chromosomes probably occurs in the telophase, for very early prophases show the chromosomes paired and twisted together, forming three spireme threads which gradually shorten and separate for mitosis."

Miss Taylor reports three chromosomes for a number of somatic cells but fails to find any cells showing six. She figures a split appearing at the ends of some of the chromosomes, which condition I find in poorly fixed material. The split indicates the beginning of the line along which two chromosomes have fused. Her failure to find six may be due to imperfect fixation, as may be judged from her figures. The importance of proper fixation has already been emphasized.

In the case of Culex pipiens it is evident that when a spermatozoa with three chromosomes unites with an egg with three chromosomes the somatic number of six is produced. The comparatively little work which has been done on somatic mitosis has tended to show that the behavior of the somatic chromosomes may not always be the same as that of those of the germ cells. (Hoy '16.) By this I do not mean that the differences which seem to exist need in any way interfere with the current cytological hypotheses, although other writers seem to think so. It is quite evident that in Culex pipiens there is no difference between the two groups of cells. It will be of interest in this connection to review the chief literature dealing with the body chromosomes. A discussion of the results will not be attempted at present.

The breaking up of the chromosomes in the somatic cells of Ascaris is too well known to need further discussion.

In Morril's work ('10) the drawings of the somatic chromosomes in Archimerus alteratus, Anasa tristis and Chalinidea vittigera are generally larger and longer than those of the reproductive cells. The relative proportions of the two sets of chromosomes appear to be the same, however. In an Anasa tristis 
embryo possessing twenty-two chromosomes he found a cell with twenty-three chromosomes and in a twenty-one chromosome Chalinidea embryo a twenty-two chromosome cell was found. Morrill noted this difference in size and stated that the chromosomes of the embryo started out long and shortened as the embryo became older.

In Seiler's paper ('14-'15) on the cytology of Lepidotera some figures of somatic chromosomes are quite noticeably larger than are the spermatogonial chromosomes. The number is the same.

Wieman ('13), in his very clear somatic figures taken from a human embryo, found the number of chromosomes to vary, and he pointed out that, "it is also known that the somatic mitoses do not always show a number identical with the premeiotic one." He reviews other similar cases which I have omitted.

In a paper on the Wandering Jew ('15) I called attention to the morphological difference between the somatic and the germinal chromosomes, the former being much more elongated. This may not be an entirely fair comparison, however, as the pollen eventually aborts and the behavior of the pollen chromosomes is pathological. In a study I have been making of the Oenothera mutant scintillans the somatic chromosomes have a wide range of number (from 15 to 21) in the cells of the same plant. It has been possible to show in this case, by special methods developed for the analysis of the chromosomes, that the 'extra' chromosomes are the product or result of fragmentation of the longer chromosomes, that the fragments divide regularly and that the total length of the chromosomes in the cells possessing extra chromosomes is the same as that of the type group. The relation of the somatic to the germinal chromosomes has been conclusively shown.

In his book, Heredity and Environment, Conklin ('15) has made a statement that would seem to sum up the suggestions of Wieman and which expresses my own belief. "Differentiations of cells are not due to the differentiations of their nuclei, but rather the reverse is true; such differentiations of nuclei as occur are due to differentiations of the cytoplasm in which they lie. 
Nevertheless differentiations do not take place in the absence of nuclear material, and it seems probable that the interaction of nucleus and cytoplasm is necessary to the formation of the new cytoplasmic substances which appear in the course of development."

\section{SUMMARY}

1. Three pairs of chromatin threads appear in the prophase. The threads are V-shaped and the apices of the V's are directed toward the same pole suggesting the anaphase position (figs. 2 to 16 ).

2. In the metaphase the threads have shortened and thickened and have become more widely separated. There are three very definite pairs or four long and two shorter chromosomes (figs. 17 to 31 ).

3. Before the division begins the position of the chromosomes is altered once again and the chromosomes come to lie side by side (figs. 25 and 31 ).

4. The spindle fibers are apparently attached to the apices of the V's.

5. The somatic chromosome number is six, as is that of the spermatogonia and ovogonia.

6. The number is the same for all the tissue studied. These include nervous tissue, limb buds, intestine, epithelium, ovarian tissue and Malphigian tubules.

7. The importance of proper fixation has been emphasized.

\section{BIBLIOGRAPHY}

Conkrin, E. G. 1915 Heredity and environment, p. 182.

HANCE, ROBERT T. 1915 Pollen development in Zebrina pendula with special reference to the ehromosomes. Bull. Torrey Bot. Club, 42.

1916 Notes on embedding in paraffin. Trans. Amer. Mic. Soc., 35.

1917. The fixation of Mammalian chromosomes. Anat. Record. April.

Hor, W. E., Jr. 1916 A study of somatic chromosomes. I. Biol. Bull., vol. 31 , no. 5 .

Metz, Charles W. 1916 Chromosome studies on the Diptera. II. Jour. Exp. Zoöl., vol. 21, no. 2.

Morrill, Charles V. 1910 Chromosomes in coroid Hemiptera. Biol. Bull., 19. 
Seiler, J. 1914-1915 Das Verhalten der Geschlechtschromosonen bei Lepidoteren. Arch f. Zellf., 13.

Stevens, N. M. 1910 The chromosomes in the germ cells of Culex. Jour. Exp. Zoöl., vol. 8.

1911 Further studies on the heterochromosomes in mosquitoes. Biol. Bull., 20.

TAylor, Monica 1915 The chromosome complex of Culex pipiens. Quart. Jour. Mic. Sc., 60.

Wiemax, H. L. 1913 Chromosomes in man. Am. Jour. Anat., 14.

All the figures are reproduced at a magnification of approximately $4500 \times$. All the drawings were made from the Flemming preparations, except figure 29, which was taken from tissue fixed in P. F. A. No. 3. The drawings are all taken from nerve tissue except figure 29 , which is from a limb bud.

\section{PLATE 1}

EXPLANATION OF FIGURES

1 Prophase showing only three threads. This cell is the product of poor fixation.

3 to 16 Prophase stages.

17 to 20 Metaphase stages, polar view. 
र्ष क्ष

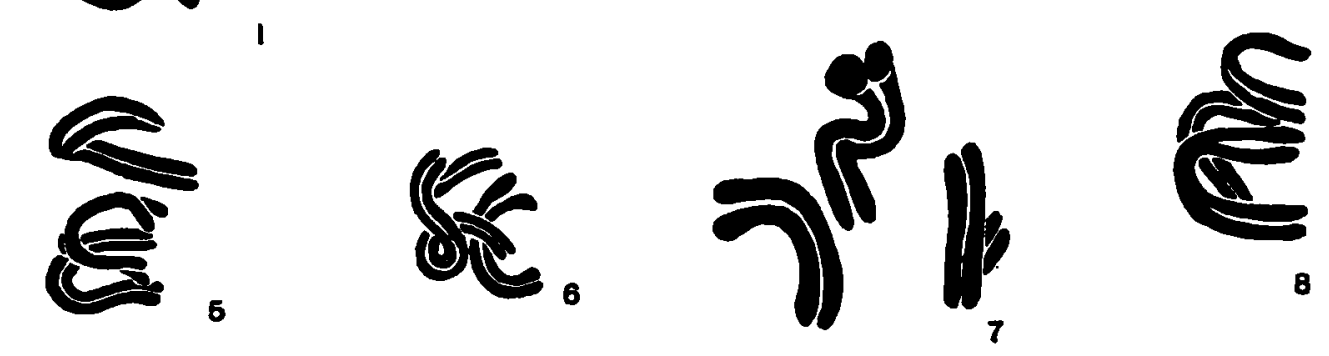

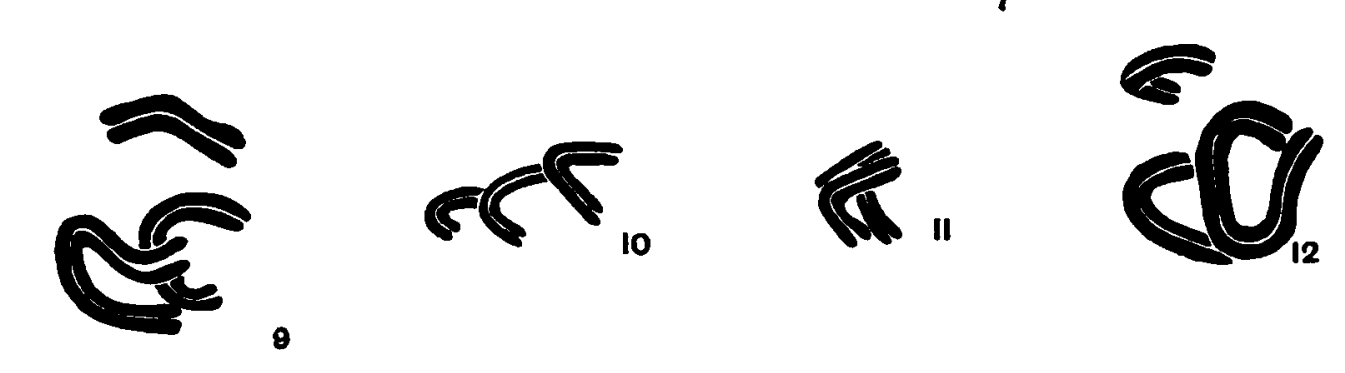

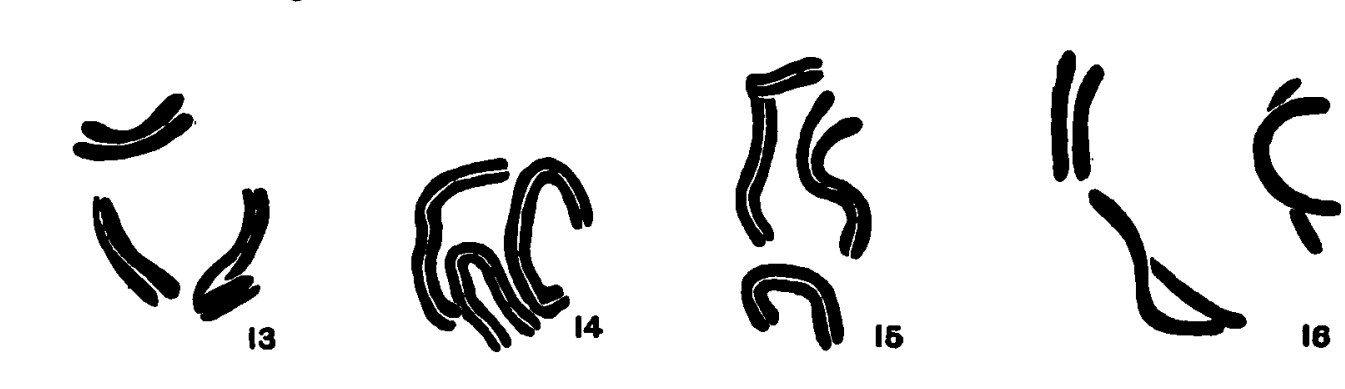

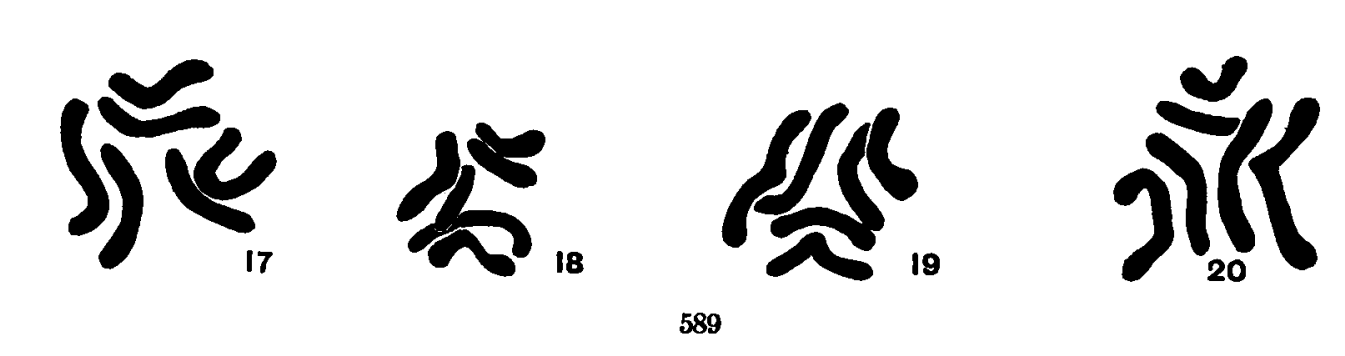




\section{PLATE 2}

EXPLANATION OF FIGURES

21 to 31 Metaphase stages, polar view.

32 to 34 Metaphase stages, side view.

35 to 37 Anaphase stages, side view.

38 and 39 Poorly fixed anaphases.

40 Anaphase stage, polar view. 
烦

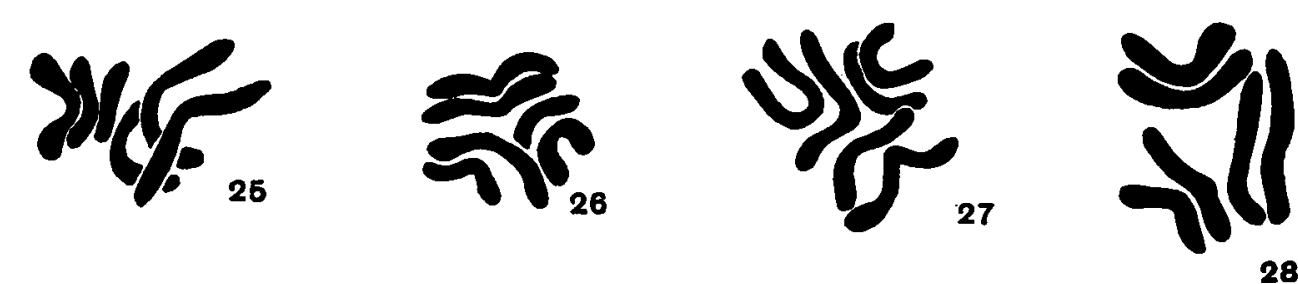

ग)

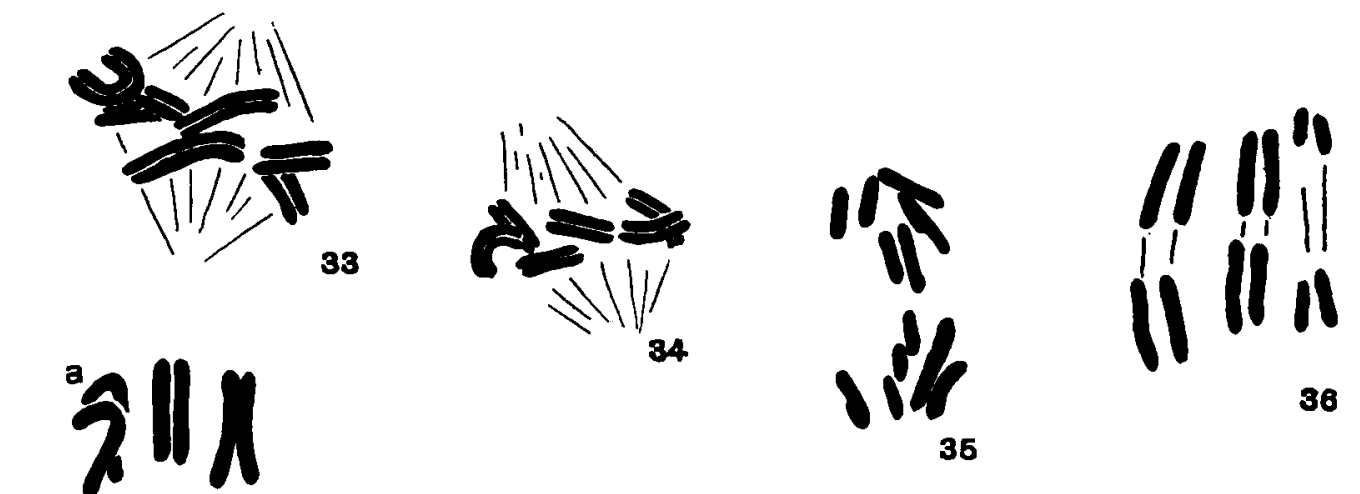

v. ${ }^{\prime \prime} w_{0}=83$ 